\title{
Prediction of SARS-CoV-2 hosts among Brazilian mammals and new coronavirus transmission chain using evolutionary bioinformatics
}

\author{
Luciano Rodrigo Lopes ${ }^{1 *}$ (D) Giancarlo de Mattos Cardillo², Natália Carvalho de Lucca Pina ${ }^{1}$, \\ Antonio Carlos da Silva Junior ${ }^{1}$, Silvana Kertzer Kasinski ${ }^{1}$ and Paulo Bandiera-Paiva ${ }^{1}$
}

\begin{abstract}
Severe acute respiratory syndrome coronavirus (SARS-CoV) and SARS-CoV-2 are thought to transmit to humans via wild mammals, especially bats. However, evidence for direct bat-to-human transmission is lacking. Involvement of intermediate hosts is considered a reason for SARS-CoV-2 transmission to humans and emergence of outbreak. Large biodiversity is found in tropical territories, such as Brazil. On the similar line, this study aimed to predict potential coronavirus hosts among Brazilian wild mammals based on angiotensin-converting enzyme 2 (ACE2) sequences using evolutionary bioinformatics. Cougar, maned wolf, and bush dogs were predicted as potential hosts for coronavirus. These indigenous carnivores are philogenetically closer to the known SARS-CoV/SARS-CoV-2 hosts and presented low ACE2 divergence. A new coronavirus transmission chain was developed in which white-tailed deer, a susceptible SARS-CoV-2 host, have the central position. Cougar play an important role because of its low divergent ACE2 level in deer and humans. The discovery of these potential coronavirus hosts will be useful for epidemiological surveillance and discovery of interventions that can contribute to break the transmission chain.
\end{abstract}

Keywords: SARS-CoV-2, Angiotensin-converting enzyme 2, Coronavirus, Brazilian mammals, White-tailed deer

\section{Background}

Severe acute respiratory syndrome coronavirus (SARS$\mathrm{CoV}$ ) and SARS-CoV-2 enter the host cell using surface (S) protein as a key component and via angiotensin-converting enzyme 2 (ACE2) receptor binding (Guruprasad 2020; Li et al. 2006). Changes in the structure of $S$ protein can reduce its affinity for ACE2 receptor and thus can impair coronavirus infectivity (Li et al. 2005). Therefore, ACE2 could be a species-specific barrier that interferes with coronavirus cross-species transmission. However, mutations in

\footnotetext{
*Correspondence: luciano.lopes@unifesp.br

'Bioinformatics and Bio-Data Science Division - Health Informatics Department, Universidade Federal de São Paulo - UNIFESP, Rua Botucatu 862 - Prédio Leal Prado (térreo), CEP: 04023-062, Sao Paulo [SP], SP, Brasil Full list of author information is available at the end of the article
}

genes coding $\mathrm{S}$ protein might be responsible for crossing the species-specific barrier and effective binding of SARSCoV-2 to new hosts (Alexander et al. 2020; Li et al. 2005). Accordingly, $\mathrm{S}$ protein is the fastest-evolving protein responsible for SARS-CoV transmission from animals to humans (Song et al. 2005).

The transmission routes of SARS-CoV, Middle East respiratory syndrome coronavirus (MERS-CoV), and SARS-CoV-2 encompass a series of wild animals (Tiwari et al. 2020). Among these animals, bats are a broad reservoir of coronavirus (Wong et al. 2020). For instance, Rhinolophus affinis, an Asian bat, is a host for a coronavirus strain having high genetic similarity with SARS$\mathrm{CoV}-2$. Additionally, betacoronavirus strains, partially similar to SARS-CoV, were detected in neotropical bat

(c) The Author(s). 2021 Open Access This article is licensed under a Creative Commons Attribution 4.0 International License, which permits use, sharing, adaptation, distribution and reproduction in any medium or format, as long as you give appropriate credit to the original author(s) and the source, provide a link to the Creative Commons licence, and indicate if changes were made. The images or other third party material in this article are included in the article's Creative Commons licence, unless indicated otherwise in a credit line to the material. If material is not included in the article's Creative Commons licence and your intended use is not permitted by statutory regulation or exceeds the permitted use, you will need to obtain permission directly from the copyright holder. To view a copy of this licence, visit http://creativecommons.org/licenses/by/4.0/ The Creative Commons Public Domain Dedication waiver (http://creativecommons.org/publicdomain/zero/1.0/) applies to the data made available in this article, unless otherwise stated in a credit line to the data. 
species such as $A$. lituratus, $C$. perspicillata and $D$. rotundus (Brandão et al. 2008; Corman et al. 2013; Góes et al. 2016). The betacoronavirus strain was found in Brazilian territory that has 178 bat species (Nogueira et al. 2014), and might favor the spillover of coronavirus to new susceptible host species.

Bats are a potential reservoir for several human pathogenic viruses, including coronavirus (Calisher et al. 2006). However, they exhibit remarkable resilience without manifestation of diseases because of their unique immune system (Brook and Dobson 2015). The high population density of bats favors viral dispersion (Calisher et al. 2006). Several species of bats fly over long distances during seasonal migrations (Popa-Lisseanu and Voigt 2009), and might be responsible for further spread of viruses to geographically distant locations. Furthermore, the use of echolocation for navigation produced by a specialized larynx can result in high dispersion of droplets and aerosols, which also facilitates viral transmission (Calisher et al. 2006).

Although SARS-like-CoV and SARS-like-CoV-2 are widely spread in bats, direct bat-to-human transmission has no evidence ( $\mathrm{Lu}$ et al. 2015; Wong et al. 2020). Therefore, an intermediate host might be involved in the transmission of coronavirus to humans by improving the affinity of $\mathrm{S}$ protein for ACE2 receptor (Wang et al. 2006). In addition, similarity of ACE2 between hosts seems to be an important fator for zoonotic transmission. In a previous study, our group reported that human ACE2 receptor showed low divergence compared with ACE2 receptor from civet or pangolin, both which are known as intermediate hosts for coronavirus outbreaks. However, human ACE2 receptor showed higher divergence than that of bat ACE2 receptor (Lopes et al. 2020). Intermediate divergences reported between human and civet/pangolin ACE2 might contribute to the transmission of SARS-CoV and SARS-CoV-2, respectively.

The increased contact between animals and humans has raised concerns about the emergence of new coronavirus outbreak. Zoonotic transmission of SARS-CoV-2 has been proved, however, the spillover of SARS-CoV-2 from humans to wild animals must be considered. Evidence within mink farms has indicated the transmission of SARS-CoV-2 between humans and mink and back to humans (Munnink et al. 2021). Moreover, feral cats that roam on and beyond the mink farms were determined to be infected by SARS-CoV-2. These cats were likely infected by SARS-CoV-2-infected minks (van Aart et al. 2021). Furthermore, owing to the detection of SARSCoV-2 in zoo animals, human-to-wild animal transmission has also been discussed (McAloose et al. 2020; Singla et al. 2020). The close contact between human population infected with SARS-CoV-2 and wild mammals might be a potential threat for new coronavirus outbreak. Based on this assumption, we aimed to study ACE2 receptor in Brazilian wild mammals to predict potential hosts for coronavirus using evolutionary bioinformatics analyses.

\section{Results}

We performed phylogenetic analysis including 34 ACE2 protein complete sequences, obtained from the NCBI Protein database (www.ncbi.nlm.nih.gov/protein/) using MrBayes V.3.2 (Ronquist et al. 2012). ACE2 sequences from 27 species of wild mammals found in Brazil, five known coronavirus hosts, Homo sapiens and A. mississippiensis (outgroup) were included in this study. ACE2 sequences from known SARS-CoV, MERS-CoV and SARS-CoV-2 hosts were included to determine the phylogenetic relationship between these animals and Brazilian wild mammals to predict potential hosts among them. The accession numbers of all sequences are listed in Supplementary Table 1. ACE2 protein sequences were aligned using MUSCLE (Edgar 2004). To construct a phylogenetic tree, the Jones-TaylorThornton model (Jones et al. 1992) with a gamma distribution for among-site rate variation $(\mathrm{JTT}+\mathrm{G}$ model) was used, selected by the model test conducted in MEGA X (Kumar et al. 2018). Additional analysis of a phylogenetic tree of cervid species, including 11 mitochondrial cytochrome b amino acid sequences (listed in Supplementary Table 1), was performed using mtREV model (general reversible Markov model-REV for mitochondrial DNA-encoded proteins) (Adachi and Hasegawa 1996), selected by the model test conducted in MEGA X (Kumar et al. 2018). Bayesian phylogenetic trees were searched for one million generations with sampling every 100 generation until the standard deviation from split frequencies was less than 0.01 . The parameters and the trees were summarized by wasting $25 \%$ of the samples obtained (burn-in). A consensus tree was constructed and was further used to determine the posterior probabilities. Phylogenetic trees were formatted using the FigTree v1.3.1 software (http://tree.bio.ed.ac.uk/software/figtree/). We further performed evolutionary divergent pairwise analysis based on the number of amino acid substitutions per site, using the MEGA X software (Kumar et al. 2018), and constructed a heatmap matrix to complement the phylogeny. To infer the evolutionary divergence, we used the ACE2 complete sequence-based alignment. We also used a concatenated alignment with four ACE2 regions containing residues involved in binding to $S$ protein of SARSCoV-2 (Supplementary file 1). ACE2 binding regions that encompass the key residues enabling interactions with SARS-CoV-2 S protein were based on previous studies (Shang et al. 2020; Brown et al. 2021). 
ACE2 phylogenetic tree (Fig. 1a), rooted in ACE2 of $A$. mississippiensis, showed two distinct clades. Clade 1 was clustered into three subclades: bats (A), ungulates (B), and felines/canids (carnivores) together with known SARS-CoV and SARS-CoV-2 hosts (C). Clade 2 is a small and outside clade composed of primates, encompassing humans. $D$. novemcinctus (armadillo) was placed distantly in the tree.
The phylogenetic tree of ACE2 sequence (Fig. 1a) revealed that clade $1 \mathrm{C}$ of SARS-CoV intermediate hosts nested with Brazilian wild carnivores. Paguma larvata (civet) is closely related to Puma concolor (cougar), whereas Nyctereutes procyonoides (raccoon dog) is closely related to $C$. brachyurus (maned wolf) and Speothos venaticus (bush dog). These close evolutionary
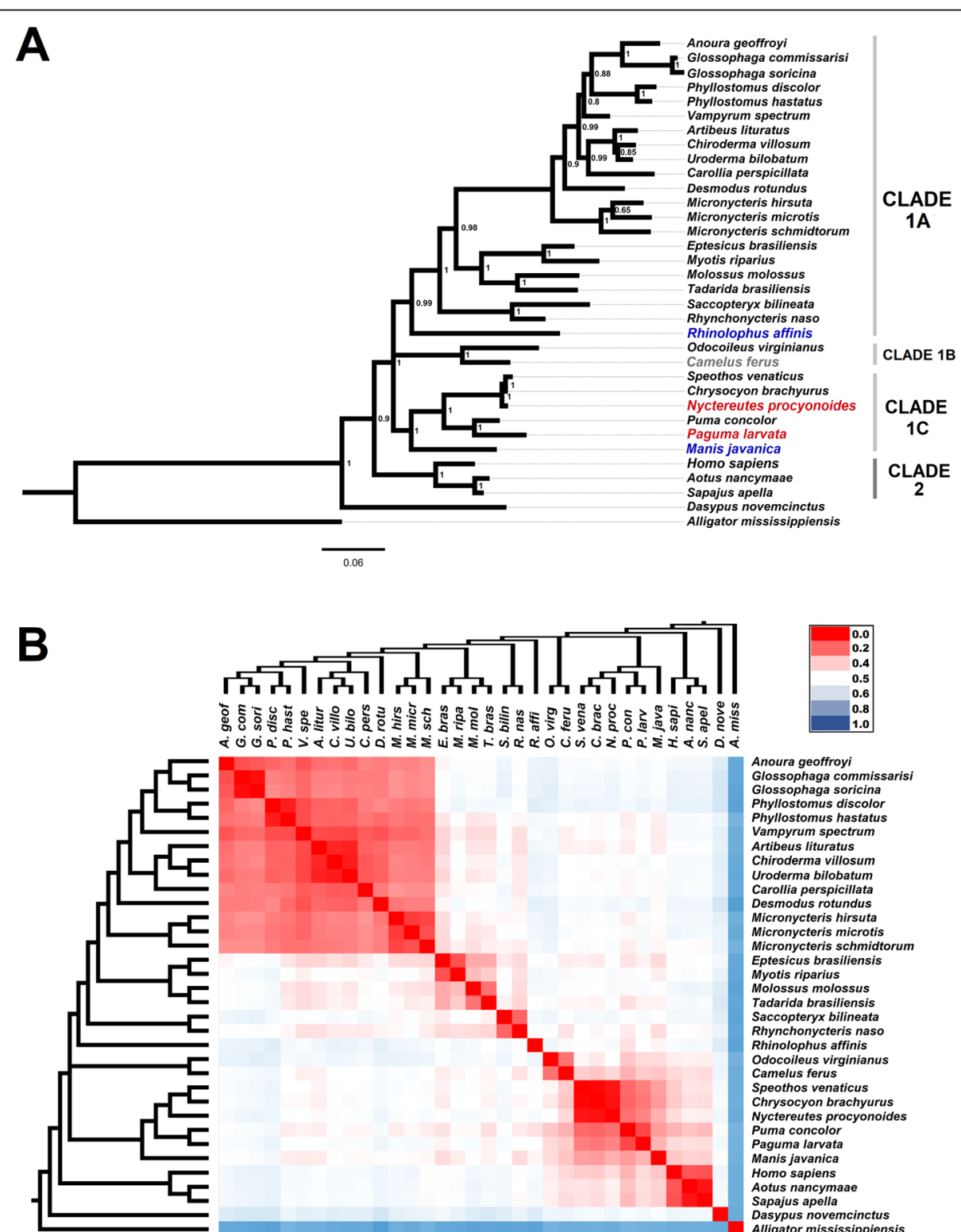

Anoura geoffroyi

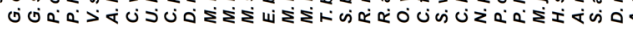

Glossophaga commissaris Glossophaga soricina Phyllostomus hastatus Vampyrum spectrum Artibeus lituratus Chiroderma villosum Uroderma bilobatum Carollia perspicillata Micronycteris hirsuta Micronycteris microtis Micronycteris schmidtorum Eptesicus brasiliensis Moliss riparius Tadarida brasiliensis Saccopteryx bilineata Rhynchonycteris naso Rhinolophus affinis Camelus ferus Speothos venaticus Chrysocyon brachyurus Nyctereutes procyonoides Puma concolor Paguma larvata Homo sapiens Aotus nancymaa Sapajus apella Dasypus novemcinctus

Fig. 1 Evolutionary analysis based on angiotensin-converting enzyme 2 (ACE2). a Phylogenetic tree included 34 amino acid sequences. The species in blue represent the known severe acute respiratory syndrome coronavirus (SARS-CoV)-2 hosts, the species in gray represent the known MERS-CoV host, and the species in red represent the known SARS-CoV hosts. The numbers in the phylogenetic tree represent the posterior probability that are the confidence values from each clade (the higher confidence is 1). Scale bar indicates the number of substitutions/site for the trees. $\mathbf{b}$ Bayesian phylogenetic tree was based on ACE2 protein. ACE2 protein sequences were aligned and used to infer the evolutionary divergence values, represented in the matrix heatmap. The heatmap color gradient represents the evolutionary divergence based on the number of amino acid substitutions/site from a pairwise comparison between sequences, from low (red) to high (blue). Evolutionary divergence analyses were conducted using the JTT matrix-based model. The heatmap were constructed using the Microsoft Excel ${ }^{\mathrm{TM}}$ software 
relationships were confirmed by low divergence between SARS-CoV hosts and the indigenous carnivores (Fig. $1 \mathrm{~b}$ and Table 1). Manis javanica (Malayan pangolin), the intermediate host of SARS-CoV-2, was placed together with cougar, maned wolf and bush dog in clade $1 \mathrm{C}$ and showed low divergence of ACE2 protein compared with these animals (Fig. 1b and Table 1), although it is not close to the Brazilian carnivores such as the civet and raccoon dog are.

ACE2-based analyses showed that humans are phylogenetically distant and evolutionarily divergent from bats. Bats were placed closer to the mammals of clades $1 \mathrm{~B}$ and $1 \mathrm{C}$ than humans from clades $1 \mathrm{~B}$ and $1 \mathrm{C}$ in the phylogenetic tree (Fig. 1a). However, the evolutionary divergence of humans from wild carnivores is lower than that from bats (Fig. $1 \mathrm{~b}$ and Table 1). Among the indigenous carnivores, cougar showed lowest divergence from human ACE2 receptor (Table 1).

An additional analysis targeting key residues based on the binding region of ACE2 protein, which are important regions in SARS-CoV-2 S protein-ACE2 interactions, revealed similarities between humans and other mammals (Table 2). Sequences from cougars had higher similiarity with those from humans; only three different ACE2 key residues involved in binding to $S$ protein were observed between them. The similarity between cougar and human sequences was even higher than the similarities within the primate group. ACE2 key residues, involved in binding to $\mathrm{S}$ protein, from bush dog, maned wolf and white-tailed deer were also highly similar to human ACE2 key residues. Human ACE2 key residues in binding regions were more similar to those of indigenous mammals than to those of known coronavirus hosts, such as camel, civet and pangolin. Evolutionary divergent analysis based on ACE2 regions containing the residues that interface with SARS-CoV-2 $\mathrm{S}$ protein of different species also showed low divergence between human and cougar and white-tailed deer (Table 2 and Fig. 2). Moreover, ACE2 binding region from cougar and deer presented a low divergence to those from indigenous bats (Fig. 2 and Supplementary Table 2). These results reinforce the potential of Brazilian mammals to serve as susceptible hosts for SARS-CoV-2. Among Brazilian bats, ACE2 key residues from Anoura geoffrey had higher similarity in comparison with those of humans. However, A. geoffrey is a known host for alphacoronavirus, but there has been no reports of this bat species harbouring betacoronavirus (Corman et al. 2013).

Our results, based on ACE2 analysis, revealed a close relationship and low divergence between the ungulates Camel ferus (camel), a known MERS-CoV host, and Odocoileus virginianus (white-tailed deer), a host susceptible to SARS-CoV-2 infection (Fig. 1 and Table 1). Additionally, the key residues in binding region of ACE2 protein of ungulates had few differences in comparison with those of human ACE2 (Table 2 and Fig. 2). MERS$\mathrm{CoV}$ transmission from camels to humans requires close exposure to be effective (Han et al. 2016). In this context, humans also come in close contact with whitetailed deer because of their hunting and use as livestock (McShea 2012). SARS-CoV-2 transmission in farmed animals (American mink) has already been reported (Munnink et al. 2021). Furthermore, deer have high population density and are broadly distributed across all American continents, that are next to urban areas. For controling the population density of deer, their hunting is considered legal in some territories (McShea 2012). In northern Brazil, white-tailed deer are hunted and their

Table 1 Angiotensin-converting enzyme 2 (ACE2) based-evolutionary divergence

\begin{tabular}{|c|c|c|c|c|c|c|c|c|c|c|c|c|c|c|}
\hline Species & A. geof & A. litu & C. pers & D. rotu & R. affi & O. virg & C. feru & S. vena & C. brac & N. proc & P. conc & P. larv & M. java & H. sapi \\
\hline \multicolumn{15}{|l|}{ Anoura geoffroyi } \\
\hline Artibeus lituratus & 0,112 & & & & & & & & & & & & & \\
\hline Carollia perspicillata & 0,133 & 0,100 & & & & & & & & & & & & \\
\hline Desmodus rotundus & 0,125 & 0,107 & 0,125 & & & & & & & & & & & \\
\hline Rhinolophus affinis & 0,283 & 0,266 & 0,262 & 0,289 & & & & & & & & & & \\
\hline Odocoileus virginianus & 0,304 & 0,272 & 0,273 & 0,302 & 0,273 & & & & & & & & & \\
\hline Camelus ferus & 0,261 & 0,235 & 0,250 & 0,265 & 0,240 & 0,115 & & & & & & & & \\
\hline Speothos venaticus & 0,264 & 0,238 & 0,252 & 0,272 & 0,230 & 0,240 & 0,202 & & & & & & & \\
\hline Chrysocyon brachyurus & 0,258 & 0,233 & 0,246 & 0,267 & 0,225 & 0,228 & 0,196 & 0,006 & & & & & & \\
\hline Nyctereutes procyonoides & 0,266 & 0,240 & 0,253 & 0,273 & 0,230 & 0,233 & 0,201 & 0,013 & 0,008 & & & & & \\
\hline Puma concolor & 0,252 & 0,231 & 0,240 & 0,267 & 0,196 & 0,196 & 0,176 & 0,106 & 0,102 & 0,106 & & & & \\
\hline Paguma larvata & 0,269 & 0,251 & 0,257 & 0,287 & 0,220 & 0,214 & 0,201 & 0,128 & 0,120 & 0,123 & 0,074 & & & \\
\hline Manis javanica & 0,254 & 0,231 & 0,242 & 0,244 & 0,219 & 0,215 & 0,193 & 0,159 & 0,154 & 0,163 & 0,155 & 0,178 & & \\
\hline Homo sapiens & 0,279 & 0,255 & 0,273 & 0,288 & 0,253 & 0,231 & 0,213 & 0,201 & 0,199 & 0,203 & 0,177 & 0,213 & 0,195 & \\
\hline
\end{tabular}




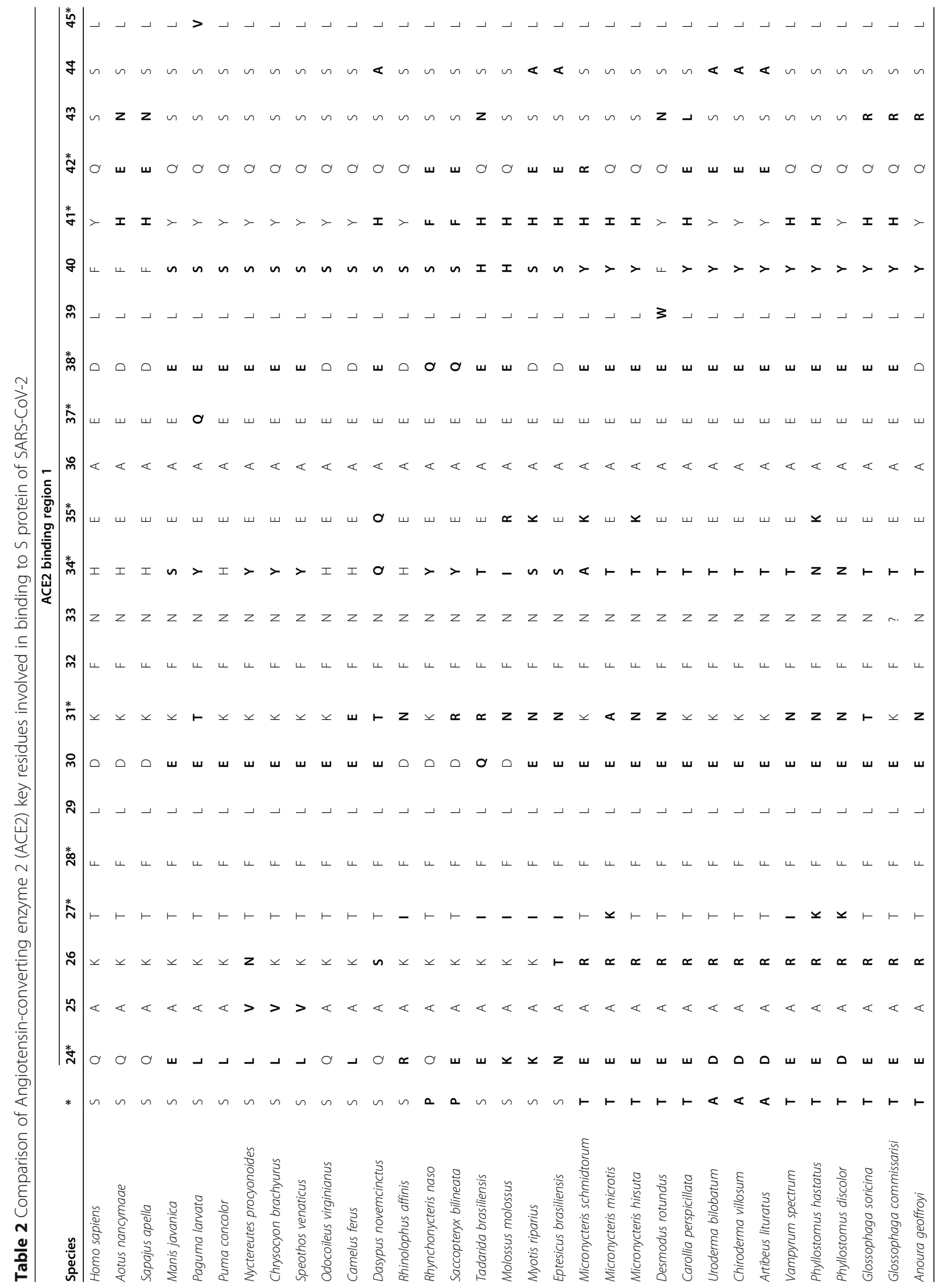




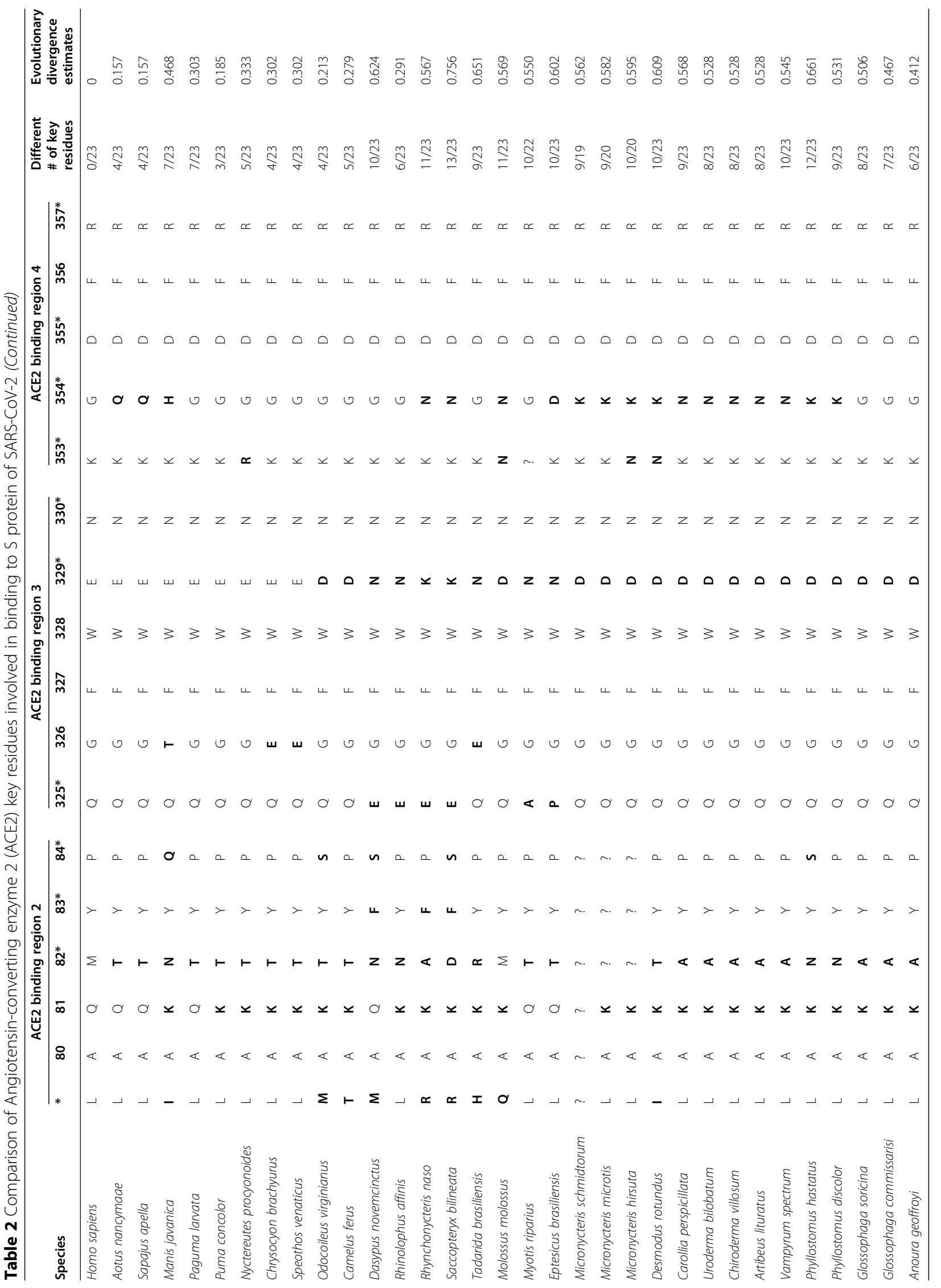




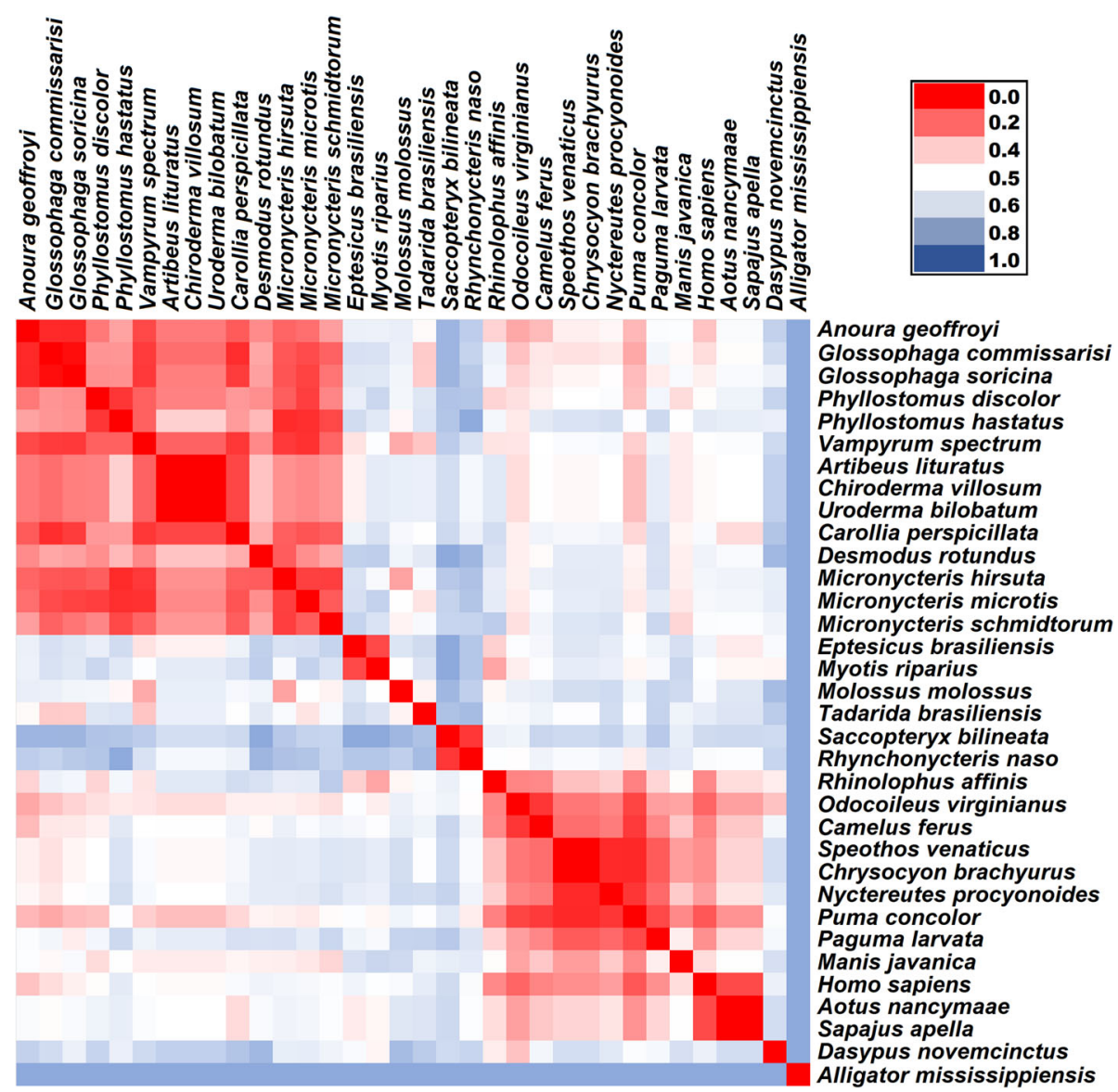

Fig. 2 Heatmap matrix was based on four ACE2 binding regions that encompass the key residues enabling interactions with the SARS-CoV-2 S protein, detailed on Table 2 and Supplementary file 1. The ACE2 binding regions were concatened and used to infer the evolutionary divergence values, represented in the matrix heatmap. The evolutionary divergence values are available in the Supplementary Table 2. The heatmap color gradients represent the evolutionary divergence based on the number of amino acid substitutions/site from a pairwise comparison between sequences, from low (red) to high (blue). Evolutionary divergence analyses were conducted using the JTT matrix-based model. The heatmap were constructed using the Microsoft Excel ${ }^{\mathrm{TM}}$ software

meat is consumed by quilombola communities (de Figueiredo et al. 2016).

Based on the close relationship between humans and white-tailed deer, and considering their susceptibility to SARS-CoV-2 infection, we proposed a scenario that represents the transmission chain of SARS-CoV-2, including the potential hosts predicted by our evolutionary bioinformatics analyses and considering the ecological features of the wild mammals (Fig. 3). White-tailed deer have intricate relationships with other wild animals and humans. For instance, white-tailed deer (and other deer species) have been frequently preyed on by cougars (Cooley et al. 2008; McShea 2012). Both the species share a large spatial area on the American continent. In some locations, cougars appear to primarily subsist on white-tailed deer during winter (Cooley et al. 2008). This situation could favor the transmission of SARS-CoV-2 from deer to cougar. In addition, our results showed low
ACE2 evolutionary divergence between deer and cougar (Table 1), which may further contribute to potential transmission. SARS-CoV-2-infected wild felines from zoos (McAloose et al. 2020) and domestic cats (Halfmann et al. 2020) may contribute to the SARS-CoV-2 transmission hypothesis of the cougars being infected by SARS-CoV-2. SARS-CoV-2 spillover from humans to cougars is possible because of substantial conflicts between the two in farming frontiers (de Souza et al. 2018; Palmeira et al. 2015).

Additional ecological interactions involving whitetailed deer place these animals at the center of potential transmission chain (Fig. 3). A study reported that $D$. rotundus feed on white-tailed deer (Sánchez-Cordero et al. 2011). The high abundance of deer may constitute an important feed resource for vampire bats. The susceptibility of $D$. rotundus toward SARS-like-CoV infections indicates that vampire bat might be infected by 


\section{Potential SARS-CoV-2 spillover chain}

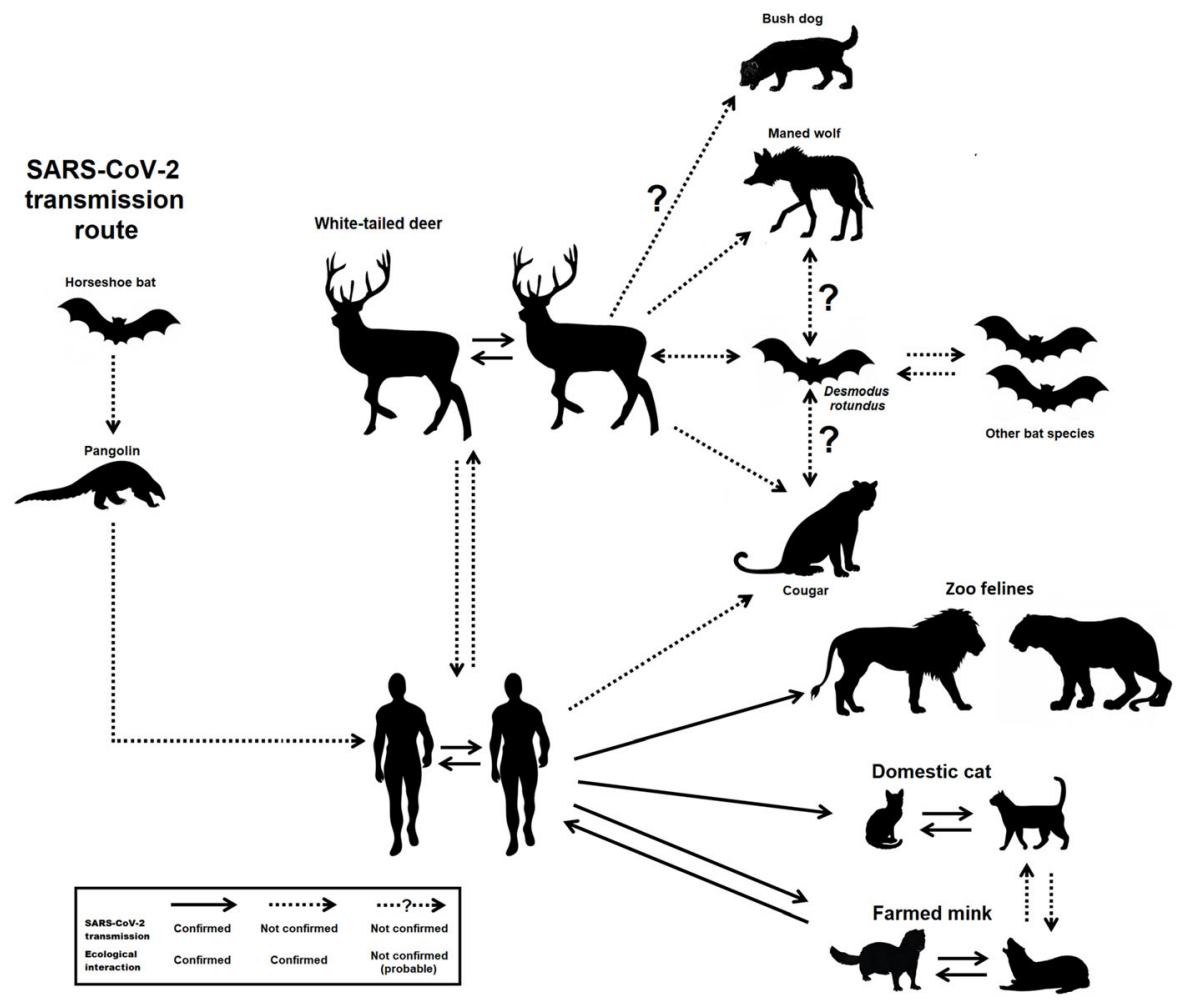

Fig. 3 Diagram displaying the potential transmission chain of severe acute respiratory syndrome coronavirus (SARS-CoV)-2 among humans and wild animals. Known SARS-CoV-2 hosts (horseshoe bat and pangolin), susceptible hosts confirmed by previous studies (white-tailed deer, mink, domestic cat, and zoo felines) and potential SARS-CoV-2 hosts (cougar, maned wolf and bush dog) predicted by bioinformatics analysis were included. (From left to right) Horseshoe bats (Rhinolophus genus), the main animal reservoir of SARS-CoV-2 (SARS-like-CoV) and Malayan pangolin, the SARS-CoV-2 intermediate host. White-tailed deer are susceptible to SARS-CoV-2 infection and are preyed by cougars, a potential SARS-CoV-2 host predicted by this study. SARS-CoV-2 may transmit from humans to cougars, considering that lions and tigers were infected by SARS-CoV-2 in the zoo. Maned Wolf, a potential SARS-CoV-2 host, can prey on other deer species. Bush dog is likely to prey on deer, but evidence is lacking. D. rotundus, a vampire bat, is a SARS-like-CoV host that can feed on white-tailed deer and other deer species. Moreover, D. rotundus could spread coronavirus to other bat species or even to cougar, maned wolf or bush dog, although there is no scientific confirmation

SARS-CoV-2 and transmit the virus to other animals. $D$. rotundus was also observed feeding on another cervid species, red brocket deer (Mazama americana) (Zortéa et al. 2018). In addition, these South American cervid are preying upon by maned wolf (Juarez and MarinhoFilho 2002) and by bush dog, according to the observation of individuals living next to wild habitat (Beisiegel and Ades 2002). Although the susceptibility of red brocket deer to SARS-CoV-2 has not yet been confirmed, all cervid species should be considered potential hosts for SARS-CoV-2 because of the close evolutionary relationship between these animals and white-tailed deer (Supplementary Fig. 1).

Taken together, connections between SARS-CoV-2 susceptible hosts with potential hosts comprise a complex network and hence might contribute to SARSCoV-2 transmission and emergence of new coronavirus strains. The history of SARS shows that coronavirus presents high variability, potential to infect wildlife and rapid evolution to adapt in new susceptible hosts, thus becoming a threat to humans (Gong and Bao 2018). SARS-like-CoV strains, frequently found in wildlife after the end of the SARS outbreak, can be implicated in SARS-CoV-2 origin (Zhang et al. 2020). High mutation rate and worldwide spread of SARS-CoV-2 contribute to the emergence of new variants (Benedetti et al. 2020). Thus, high mutation rates of SARS-CoV-2 may favor virus transmission in susceptible wild hosts.

Considering ACE2 receptor as a transmission barrier that interferes with the coronavirus spillover to humans, a low divergence between ACE2 receptors of susceptible hosts may favor cross-species transmission. The close evolutionary relationship between the known coronavirus intermediate hosts and Brazilian mammals based on ACE2 sequences showed that other hosts might be also be involved in the chain. Our results suggest that cougar, maned wolf, bush dog, and white-tailed deer, as well as their relative species, are potential hosts for 
SARS-CoV-2 transmission. We focused on whitetailed deer as a susceptible SARS-CoV-2 host because of their increased population, wide distribution, and close contact with humans and other potential hosts such as cougars. In this context, white-tailed deer and cougar (prey and predator) could be involved in coronavirus transmission together with tropical bats susceptible to betacoronavirus. The central role of whitetailed deer during SARS-CoV-2 outbreak, as well camels during MERS outbreak, can make them important coronavirus reservoirs. However, these results must be confirmed through animal experiments and studies to detect coronavirus strains and assess the ability of these animals to serve as susceptible hosts.

In Brazil, SARS-CoV-2 infections have been rapidly spreading, since the beginning of the coronavirus disease 2019 (COVID-19) pandemic, favoring the emergence of new variants (da Silva and Pena 2021). Thus, a high incidence of SARS-CoV-2 cases in populations that live in proximity to wild habitats, which harbor a large diversity of mammals, can be an additional and critical scenario of new emerging coronavirus strains in Brazilian territories. Genomic surveillance should be widely implemented to identify new variants and establish measures to control SARS-CoV-2 transmission. However, in the context of Brazil, SARS-CoV-2 surveillance has been slow (da Silva and Pena 2021). The discovery of potential hosts for coronaviruses is essential for epidemiological surveillance. Moreover, coronavirus transmission chain can be broken using effective intervention if all players involved in the chain are identified. Therefore, the surveillance of SARS-CoV-2 in domestic or wild animals, specially those with low divergence in the ACE2 receptor when compared to that of humans, should be broadly applied. Brazil should join forces to promote multi-sectoral responses, reducing the impact of the SARS-CoV-2 pandemic and consequently preventing the emergence of new coronavirus outbreaks.

\footnotetext{
Abbreviations

ACE2: Angiotensin-converting enzyme 2; COVID-19: Coronavirus disease 2019; JTT: Jones-Taylor-Thornton; MERS: Middle East respiratory syndrome coronavirus; MERS-CoV: Middle East respiratory syndrome coronavirus coronavirus; mtREV: General reversible Markov model for mitochondrial DNAencoded proteins; NCBI: National Center for Biotechnology Information; S: surface; SARS: Severe acute respiratory syndrome; SARS-CoV: Severe acute respiratory syndrome coronavirus; SARS-CoV-2: Severe acute respiratory syndrome coronavirus 2
}

\section{Supplementary Information}

The online version contains supplementary material available at https://doi. org/10.1186/s44149-021-00020-w.

Additional file 1: Supplementary Table 1. Protein accession numbers.
Additional file 2. ACE2 key residues interfacing with SARS-CoV-2 S protein.

Additional file 3: Supplementary Table 2. Estimates of evolutionary divergence between ACE2 regions that encompass the key residues enabling interactions with the SARS-CoV-2 S protein. The number of amino acid substitutions per site between sequences are shown. Evolutionary analyses were performed using MEGA X software. Analyses were conducted using the JTT matrix-based model. The rate variation among sites was modeled with a gamma distribution. This analysis involved 34 amino acid sequences aligned using MUSCLE. All ambiguous positions were removed for each sequence pair (pairwise deletion option). A total of 40 positions were included in the final dataset.

Additional file 4: Supplementary Figure 1. Bayesian tree based on 11 cervid mitochondrial cytochrome $b$ amino acid sequences. Phylogeny was performed using MrBayes 3.2.v. and the mtREV+G. Values of posterior probabilities are shown at the nodes of interest. The scale bar indicates the number of substitutions/site for the trees. Phylogenetic tree was formatted using the FigTree v1.3.1 software (http://tree.bio.ed.ac.uk/ software/figtree/).

\section{Acknowledgments}

The authors thank Universidade Federal de São Paulo (Unifesp) for the support.

\section{Code availability}

Not applicable.

\section{Authors' contributions}

LRL conceived the work with the GMC, PBP and, ACSJ contributions. The NCLP and LRL obtained and curated the data. LRL, PBP and, GMC made inferences and results analyses. LRL wrote the draft paper with GMC, PBP, NCLP, SKK and ACSI contributions. All authors contributed to the writing of the manuscript. The author(s) read and approved the final manuscript.

\section{Funding}

Not applicable.

\section{Availability of data and materials}

All the data obtained from the NCBI Protein and NCBI GenBank databases included in this research study presented accession code/numbers for research or reanalysis.

\section{Declarations}

Ethics approval and consent to participate

This research included secondary biological data with no possibility of individual identification. The Unifesp Research Ethics Committee was consulted and it was determined that this study did not require ethical approval.

\section{Consent for publication}

Not applicable.

\section{Competing interests}

The authors state that there is no conflict of interest.

\section{Author details}

'Bioinformatics and Bio-Data Science Division - Health Informatics Department, Universidade Federal de São Paulo - UNIFESP, Rua Botucatu 862 - Prédio Leal Prado (térreo), CEP: 04023-062, Sao Paulo [SP], SP, Brasil.

${ }^{2}$ Department of Neurology and Neurosurgery, Universidade Federal de São Paulo - UNIFESP, Sao Paulo [SP], SP, Brasil.

Received: 4 June 2021 Accepted: 11 August 2021

Published online: 26 September 2021

\section{References}

Adachi, J., and M. Hasegawa. 1996. Model of amino acid substitution in proteins encoded by mitochondrial DNA. Journal of Molecular Evolution 42 (4): 459468. https://doi.org/10.1007/BF02498640. 
Alexander, Matthew R., Clara T. Schoeder, Jacquelyn A. Brown, Charles D. Smart, Chris Moth, John P. Wikswo, John A. Capra, Jens Meiler, Wenbiao Chen, and Meena S. Madhur. 2020. Predicting susceptibility to SARS-CoV-2 infection based on structural differences in ACE2 across species. The FASEB Journal 34 (12): 15946-15960. https://doi.org/10.1096/fj.202001808R.

Beisiegel, Beatriz De Mello, and César Ades. 2002. The behavior of the bush dog (Speothos Venaticus Lund, 1842) in the Field: A review. Revista de Etologia 4 (1): 17-23.

Benedetti, Francesca, Maria Pachetti, Bruna Marini, Rudy Ippodrino, Massimo Ciccozzi, and Davide Zella. 2020. SARS-CoV-2: March toward adaptation. Journal of Medical Virology. 92 (11): 2274-2276. https://doi.org/10.1002/ jmv.26233.

Brandão, Paulo Eduardo, Karin Scheffer, Laura Yaneth Villarreal, Samira Achkar, Rafael de Novaes Oliveira, Willian de Oliveira Fahl, Juliana Galera Castilho, Ivanete Kotait, and Leonardo José Richtzenhain. 2008. A coronavirus detected in the vampire bat Desmodus Rotundus. The Brazilian Journal of Infectious Diseases: An Official Publication of the Brazilian Society of Infectious Diseases 12 (6): 466-468. https://doi.org/10.1590/s1413-86702008000600003.

Brook, Cara E., and Andrew P. Dobson. 2015. Bats as 'special' reservoirs for emerging zoonotic pathogens. Trends in Microbiology 23 (3): 172-180. https://doi.org/10.1016/j.tim.2014.12.004.

Brown, Emily E.F., Reza Rezaei, Taylor R. Jamieson, Jaahnavi Dave, Nikolas T. Martin, Ragunath Singaravelu, and Mathieu J. F. Crupi, et al. 2021. Characterization of critical determinants of ACE2-SARS CoV-2 RBD interaction. International Journal of Molecular Sciences 22 (5): 2268. https://doi. org/10.3390/ijms22052268.

Calisher, Charles H., James E. Childs, Hume E. Field, Kathryn V. Holmes, and Tony Schountz. 2006. Bats: Important reservoir hosts of emerging viruses. Clinical Microbiology Reviews 19 (3): 531-545. https://doi.org/10.1128/CMR.00017-06.

Cooley, Hilary S., Hugh S. Robinson, Robert B. Wielgus, and Catherine S. Lambert. 2008. Cougar prey selection in a white-tailed deer and mule deer community. The Journal of Wildlife Management 72 (1): 99-106. https://doi. org/10.2193/2007-060.

Corman, Victor Max, Andrea Rasche, Thierno Diawo Diallo, Veronika M. Cottontail, Andreas Stöcker, Breno Frederico de Carvalho Dominguez Souza, Jefferson Ivan Corrêa, et al. 2013. Highly diversified coronaviruses in Neotropical bats. The Journal of General Virology 94 (Pt 9): 1984-1994. https://doi.org/10.1099/ vir.0.054841-0.

da Silva, Severino Jefferson Ribeiro, and Lindomar Pena. 2021. Collapse of the public health system and the emergence of new variants during the second wave of the COVID-19 pandemic in Brazil. One Health 13 (December): 100287. https://doi.org/10.1016/j.onehlt.2021.100287.

de Figueiredo, Rodrigo Augusto Alves, Flávio Bezerra Barros, Rodrigo Augusto Alves de Figueiredo, and Flávio Bezerra Barros. 2016. Caçar, preparar e comer o 'bicho do mato': práticas alimentares entre os quilombolas na Reserva Extrativista Ipaú-Anilzinho (Pará). Boletim do Museu Paraense Emílio Goeldi. Ciências Humanas 11 (3): 691-713. https://doi.org/10.1590/1981.8122201 6000300009

de Souza, Júlio César, Rosana Moreira da Silva, Marcos Paulo Rezende Gonçalves, Rodrigo José Delgado Jardim, and Scott H. Markwith. 2018. Habitat use, ranching, and human-wildlife conflict within a fragmented landscape in the Pantanal, Brazil. Biological Conservation 217 (January): 349-357. https://doi. org/10.1016/j.biocon.2017.11.019.

Edgar, Robert C. 2004. MUSCLE: Multiple sequence alignment with high accuracy and high throughput. Nucleic Acids Research 32 (5): 1792-1797. https://doi. org/10.1093/nar/gkh340

Góes, Luiz Gustavo Bentim, Angélica Cristine de Almeida Campos, Cristiano de Carvalho, Guilherme Ambar, Luzia Helena Queiroz, Ariovaldo Pereira CruzNeto, Muhammad Munir, and Edison Luiz Durigon. 2016. Genetic diversity of bats coronaviruses in the Atlantic Forest hotspot biome, Brazil. Infection, Genetics and Evolution: Journal of Molecular Epidemiology and Evolutionary Genetics in Infectious Diseases 44 (October): 510-513. https://doi.org/10.1016/j. meegid.2016.07.034.

Gong, Shu-ran, and Lin-lin Bao. 2018. The Battle against SARS and MERS coronaviruses: Reservoirs and animal models. Animal Models and Experimental Medicine 1 (2): 125-133. https://doi.org/10.1002/ame2.12017.

Guruprasad, Lalitha. 2020. Human coronavirus spike protein-host receptor recognition. Progress in Biophysics and Molecular Biology 161: 39-53. https:// doi.org/10.1016/j.pbiomolbio.2020.10.006.

Halfmann, Peter J., Masato Hatta, Shiho Chiba, Tadashi Maemura, Shufang Fan, Makoto Takeda, Noriko Kinoshita, Shin-ichiro Hattori, Yuko Sakai-Tagawa,
Kiyoko Iwatsuki-Horimoto, Masaki Imai, and Yoshihiro Kawaoka. 2020. Transmission of SARS-CoV-2 in domestic cats. New England Journal of Medicine 383 (6): 592-594. https://doi.org/10.1056/NEJMc2013400.

Han, Hui-Ju, Hao Yu, and Yu. Xue-Jie. 2016. Evidence for zoonotic origins of Middle East respiratory syndrome coronavirus. The Journal of General Virology 97 (2): 274-280. https://doi.org/10.1099/jgv.0.000342.

Jones, David T., William R. Taylor, and Janet M. Thornton. 1992. The rapid generation of mutation data matrices from protein sequences. Bioinformatics 8 (3): 275-282. https://doi.org/10.1093/bioinformatics/8.3.275.

Juarez, Keila Macfadem, and Jader Marinho-Filho. 2002. Diet, habitat use, and home ranges of sympatric canids in Central Brazil. Journal of Mammalogy 83 (4): 925-933. https://doi.org/10.1644/1545-1542(2002)083< 0925:DHUAHR>2.0.CO;2.

Kumar, Sudhir, Glen Stecher, Michael Li, Christina Knyaz, and Koichiro Tamura. 2018. MEGA X: Molecular evolutionary genetics analysis across computing platforms. Molecular Biology and Evolution 35 (6): 1547-1549. https://doi.org/1 0.1093/molbev/msy096.

Li, Wenhui, Swee-Kee Wong, Fang Li, Jens H. Kuhn, I-Chueh Huang, Hyeryun Choe, and Michael Farzan. 2006. Animal origins of the severe acute respiratory syndrome coronavirus: Insight from ACE2-S-protein interactions. Journal of Virology 80 (9): 4211-4219. https://doi.org/10.1128/JVl.80.9.4211-4219.2006.

Li, Wenhui, Chengsheng Zhang, Jianhua Sui, Jens H. Kuhn, Michael J. Moore, Shiwen Luo, Swee-Kee Wong, I-Chueh Huang, Keming Xu, Natalya Vasilieva, Akikazu Murakami, Yaqing He, Wayne A. Marasco, Yi Guan, Hyeryun Choe, and Michael Farzan. 2005. Receptor and viral determinants of SARScoronavirus adaptation to human ACE2. The EMBO Journal 24 (8): 1634-1643. https://doi.org/10.1038/sj.emboj.7600640.

Lopes, Luciano Rodrigo, Giancarlo de Mattos Cardillo, and Paulo Bandiera Paiva. 2020. Molecular evolution and phylogenetic analysis of SARS-CoV-2 and hosts ACE2 protein suggest Malayan pangolin as intermediary host. Brazilian Journal of Microbiology 51 (4): 1593-1599. https://doi.org/10.1007/s42770-02000321-1.

Lu, Guangwen, Qihui Wang, and George F. Gao. 2015. Bat-to-human: Spike features determining 'host jump' of coronaviruses SARS-CoV, MERS-CoV, and beyond. Trends in Microbiology 23 (8): 468-478. https://doi.org/10.1016/j.tim.2 015.06.003.

McAloose, Denise, Melissa Laverack, Leyi Wang, Mary Lea Killian, Leonardo C. Caserta, Fangfeng Yuan, and Patrick K. Mitchell, et al. 2020. From people to Panthera: Natural SARS-CoV-2 infection in tigers and lions at the Bronx zoo. MBio 11 (5). https://doi.org/10.1128/mBio.02220-20.

McShea, William J. 2012. Ecology and Management of White-Tailed Deer in a changing world. Annals of the New York Academy of Sciences 1249 (February): 45-56. https://doi.org/10.1111/j.1749-6632.2011.06376.x.

Munnink, Bas B. Oude, Reina S. Sikkema, David F. Nieuwenhuijse, Robert Jan Molenaar, Emmanuelle Munger, Richard Molenkamp, Arco van der Spek, et al. 2021. Transmission of SARS-CoV-2 on mink farms between humans and mink and back to humans. Science 371 (6525): 172-177. https://doi.org/1 0.1126/science.abe5901

Nogueira, Marcelo Rodrigues, Isaac Passos de Lima, Ricardo Moratelli, Valéria da Cunha Tavares, Renato Gregorin, and Adriano Lúcio Peracchi. 2014. Checklist of Brazilian bats, with comments on original records. Check List 10 (4): 808821. https://doi.org/10.15560/10.4.808.

Palmeira, Francesca Belem Lopes, Cristiano Trapé Trinca, and Claudio Maluf Haddad. 2015. Livestock predation by Puma (Puma Concolor) in the highlands of a southeastern Brazilian Atlantic Forest. Environmental Management 56 (4): 903-915. https://doi.org/10.1007/s00267-015-0562-5.

Popa-Lisseanu, Ana G., and Christian C. Voigt. 2009. Bats on the move. Journal of Mammalogy 90 (6): 1283-1289. https://doi.org/10.1644/09-mamm-s-130r2.1.

Ronquist, Fredrik, Maxim Teslenko, Paul van der Mark, Daniel L. Ayres, Aaron Darling, Sebastian Höhna, Bret Larget, Liu Liang, Marc A. Suchard, and John P. Huelsenbeck. 2012. MrBayes 3.2: Efficient Bayesian phylogenetic inference and model choice across a large model space. Systematic Biology 61 (3): 539 542. https://doi.org/10.1093/sysbio/sys029.

Sánchez-Cordero, Víctor, Francisco Botello, Gloria Magaña-Cota, and Jesús Iglesias. 2011. Vampire Bats, Desmodus Rotundus, Feeding on WhiteTailed Deer, Odocoileus Virginianus. 75 (1): 91-92. https://doi.org/10.1515/ mamm.2010.065.

Shang, Jian, Gang Ye, Ke Shi, Yushun Wan, Chuming Luo, Hideki Aihara, Qibin Geng, Ashley Auerbach, and Fang Li. 2020. Structural basis of receptor recognition by SARS-CoV-2. Nature 581 (7807): 221-224. https://doi.org/10.1 038/s41586-020-2179-y. 
Singla, Rubal, Abhishek Mishra, Rupa Joshi, Sonali Jha, Amit Raj Sharma, Sujata Upadhyay, Phulen Sarma, Ajay Prakash, and Bikash Medhi. 2020. Human animal interface of SARS-CoV-2 (COVID-19) transmission: A critical appraisal of scientific evidence. Veterinary Research Communications 44 (3-4): 119-130. https://doi.org/10.1007/s11259-020-09781-0.

Song, Huai-Dong, Tu Chang-Chun, Guo-Wei Zhang, Sheng-Yue Wang, Kui Zheng, Lian-Cheng Lei, Qiu-Xia Chen, et al. 2005. Cross-host evolution of severe acute respiratory syndrome coronavirus in palm civet and human. Proceedings of the National Academy of Sciences of the United States of America 102 (7): 2430-2435. https://doi.org/10.1073/pnas.0409608102.

Tiwari, Ruchi, Kuldeep Dhama, Khan Sharun, Mohd lqbal Yatoo, Yashpal Singh Malik, Rajendra Singh, Izabela Michalak, Sah Ranjit, D. Katterine BonillaAldana, and Alfonso J. Rodriguez-Morales. 2020. COVID-19: Animals, veterinary and zoonotic links. The Veterinary Quarterly 40 (1): 169-182. https:// doi.org/10.1080/01652176.2020.1766725.

van Aart, Anna E., Francisca C. Velkers, Egil A.J. Fischer, Els M. Broens, Herman Egberink, Shan Zhao, Marc Engelsma, et al. 2021. SARS-CoV-2 infection in cats and dogs in infected mink farms. Transboundary and Emerging Diseases. https://doi.org/10.1111/tbed.14173.

Wang, Lin-Fa, Zhengli Shi, Shuyi Zhang, Hume Field, Peter Daszak, and Bryan T. Eaton. 2006. Review of bats and SARS. Emerging Infectious Diseases 12 (12): 1834-1840. https://doi.org/10.3201/eid1212.060401.

Wong, Gary, Yu-Hai Bi, Qi-Hui Wang, Xin-Wen Chen, Zhi-Gang Zhang, and YongGang Yao. 2020. Zoonotic origins of human coronavirus 2019 (HCoV-19 / SARS-CoV-2): Why is this work important? Zoological Research 41 (3): 213219. https://doi.org/10.24272/j.issn.2095-8137.2020.031

Zhang, Liangsheng, Fu-ming Shen, Fei Chen, and Zhenguo Lin. 2020. Origin and evolution of the 2019 novel coronavirus. Clinical Infectious Diseases 71 (15): 882-883. https://doi.org/10.1093/cid/ciaa112.

Zortéa, Marlon, Diego A. Silva, Analice M. Calaça, Marlon Zortéa, Diego A. Silva, and Analice M. Calaça. 2018. Susceptibility of targets to the vampire bat Desmodus Rotundus are proportional to their abundance in Atlantic Forest fragments? Iheringia. Série Zoologia 108 (0). https://doi.org/10.1590/1678-4 $766 \mathrm{e} 2018037$.

\section{Publisher's Note}

Springer Nature remains neutral with regard to jurisdictional claims in published maps and institutional affiliations.

Ready to submit your research? Choose BMC and benefit from:

- fast, convenient online submission

- thorough peer review by experienced researchers in your field

- rapid publication on acceptance

- support for research data, including large and complex data types

- gold Open Access which fosters wider collaboration and increased citations

- maximum visibility for your research: over $100 \mathrm{M}$ website views per year

At $\mathrm{BMC}$, research is always in progress.

Learn more biomedcentral.com/submissions 